\title{
A Prenatal Diagnosis and Repair of Spina Bifida
}

Danielle Bishop ${ }^{1}$, Najma Aijaz ${ }^{1}$, Lynnette Mazur ${ }^{1 *}$

${ }^{1}$ Department of Pediatrics, University of Texas, Houstan, USA.

*Corresponding author: Lynnette Mazur, Department of Pediatrics, Baylor Medical School at the University of Texas, Houstan, USA.

Received Date: April 23, 2021; Accepted Date: April 30, 2021; Published Date; July 19, 2021

Citation: Bishop D, Aijaz N, Mazur L. (2021) A Prenatal Diagnosis and Repair of Spina Bifida. J. Surg Case Repo and Imag. 4(5); DOI:10.31579/2690-1897/073

Copyright: ( 2021 Lynnette Mazur., This is an open-access article distributed under the terms of the Creative Commons Attribution License, which permits unrestricted use, distribution, and reproduction in any medium, provided the original author and source are credited

\section{Introduction}

A 34 year-old G2P1 woman at 23 weeks gestation was referred to The Fetal Center for abnormal findings on a routine prenatal ultrasound (U/S). Magnetic resonance imaging (MRI) confirmed a single male fetus with spina bifida (SB) extending from the L4 to the S1 level. Figure 1 Additional findings included ventriculomegaly $(15 \mathrm{~mm}$ in each lateral ventricle), cerebellar herniation to the $\mathrm{C} 2$ level (Chiari malformation), and a lemon sign, (concavity of the parietal bones). Figure 2 The family history was negative for SB and the only medication the mother was taking were the recommended prenatal vitamins.

\section{Diagnosis}

$\mathrm{SB}$, a congenital defect of the spine in which part of the spinal cord and its meninges are exposed through a gap in the backbone, is typically detected by U/S in the second trimester. A family history of SB, poor maternal nutrition, or an elevated maternal serum alpha-fetal-protein (AFP) may heighten suspicion and prompt further testing.

\section{Treatment}

Before the 2011 Management of Meningomyelocele Study (MOMS) was published, the standard of care for SB was surgical closure of the defect shortly after birth. The MOMS trial showed that prenatal repair could limit damage to exposed spinal contents, arrest spinal fluid leakage, reverse hindbrain herniation, and improve fetal outcomes. Repair, usually between 19 and 25 weeks gestation is done by hysterotomy or a laparoscopic procedure [1].

In the MOMS trial, 183 expectant mothers were randomized to either prenatal or postnatal repair. Results showed that prenatal repair reduced the need for shunt placement (40\% vs $82 \%)$, decreased hindbrain herniation (64\% vs 96\%), and improved independent walking by 30 months ( $42 \%$ vs $21 \%$ ). No difference in cognitive scoring between groups was noted [1].

\section{Management}

When SB is found on prenatal screening other anomalies such as oral clefts, talipes equinovarus, and cardiovascular or renal malformations and chromosomal abnormalities are important to detect. Amniocentesis for chromosomal microarray can be performed and screening for additional malformations can be done via U/S and/or MRI. Ideally, testing before 20 weeks gestation allows time for further diagnostic or therapeutic procedures.

If prenatal repair is considered, the mother can be referred to a fetal center experienced with SB repair. If the mother meets the inclusion criteria, the maternal and fetal risks and benefits and the expected long-term outcomes are discussed. Table 1 After the procedure, the mother remains in the hospital on tocolytic medications for about a week to prevent preterm labor. Delivery is scheduled via cesarean section at 37 weeks to avoid the risk of uterine rupture. Parents are counseled that the recurrence risk of $\mathrm{SB}$ is 1 in 20 in subsequent pregnancies.

After birth, ongoing neurologic, orthopedic, pediatric, and urologic care are important. Neurologically, the signs and symptoms of hydrocephalus, hindbrain herniation, and tethered cord are monitored as the child grows. ${ }^{2}$ Orthopedically, the severity of disability is correlated with the level of the defect. Table 2 However, infants who undergo prenatal repair are three times as likely to have muscle function that is greater than two levels better than expected. ${ }^{1}$ Urologically, almost all children with SB have compromised urinary tract function due to sacral innervation of the bladder. Many require clean intermittent catheterization (CIC) and daily anticholinergic medications to decrease incontinence and susceptibility to urinary tract infections. Although the urologic benefits of prenatal repair remain unproven, small studies show a decrease in the need for CIC and medications. ${ }^{3,4}$ Furthermore, because children from the MOMS trial are not yet adults, comparison of sexual function between groups remains unknown. ${ }^{5,6}$ However, paternity rates of $70 \%$ have been reported.

\section{Discussion}

With an annual incidence of SB at 3.4 per 10,000 live births in the US, almost 4,000 children a year are affected. Although food supplementation with folic acid has decreased the prevalence, other risk factors such as diabetes, obesity, maternal fever, poor nutrition, family history, and certain medications contribute to its development. However, because 95\% of cases have no known risk factors, screening of all pregnant women via maternal serum AFP and/or second trimester U/S is crucial as the window of time between detection and the potential for intervention is only a few weeks.

While the MOMS trial documented improved outcomes for infants with $\mathrm{SB}$, discussion of the maternal and fetal risks and benefits are important in the couple's decision-making. Maternal risks associated with prenatal surgery include chorioamniotic membrane separation, oligohydramnios, 
placental abruption, spontaneous membrane rupture, uterine dehiscence, and preterm delivery. Chorioamniotic membrane separation occurred in $26 \%$ of prenatal repair cases in the MOMS trial (vs $0 \%$ in the postnatal repair group) and can lead to the formation of amniotic bands and umbilical cord strangulation. ${ }^{1}$ Oligohydramnios occurred in $21 \%$ (vs 4\%), placental abruption in $6 \%$ (vs $0 \%$ ), and spontaneous membrane rupture in $46 \%$ (vs $8 \%$ ). A third of patients in the prenatal group had areas of uterine dehiscence or scaring at the time of delivery. The average gestational age for the prenatal group was 34.1 weeks, $13 \%$ being born before 30 weeks, compared to 37.3 weeks and no deliveries before 30 weeks in the postnatal group. There were no maternal deaths in either group and there was no difference in perinatal mortality rate between groups [1]. Lastly, while the degree of hydrocephalus has improved with prenatal repair, the need for a shunt is directly correlated with ventricle size. Specifically, patients with ventricles $\geq 15 \mathrm{~mm}$ showed no difference in shunt placement [1].

\section{Patient Outcome}

Although the MOMs inclusion criteria were stringent, our patient was one of about $25 \%$ of referred mothers who met the inclusion criteria for fetal repair. The couple decided to proceed with the surgery and at 25 weeks gestation a five-hour open repair was performed. The mother was hospitalized for one week to monitor for signs of infection and preterm labor before being discharged home. She continued on nifedipine for tocolysis and a scheduled cesarean section was performed at 37 weeks. Both mother and son were discharged home after two weeks.

\begin{tabular}{|c|c|}
\hline \multicolumn{2}{|c|}{ Table 1: Maternal and Fetal Inclusion Criteria for Prenatal Repair of Meningomyelocele } \\
\hline Maternal & Fetal \\
\hline Age older than 18 years & SB at T1-S1 level \\
\hline Singleton pregnancy & Hindbrain herniation confirmed by MRI \\
\hline BMI $\left(\mathrm{kg} / \mathrm{m}^{2}\right) 40$ or less & No kyphosis $30^{\circ}$ or greater \\
\hline Gestational age $190 / 7-256 / 7$ & Normal karyotype or FISH \\
\hline Cervical length greater than $20 \mathrm{~mm}$ & US residency \\
\hline No history of incompetent cervix & No significant anomaly not related to SB \\
\hline No existing or planned cerclage in the current pregnancy & \\
\hline No history of uterine anomaly or uterine leiomyomata & \\
\hline $\begin{array}{l}\text { No history of previous hystero tomy in the } \\
\text { active segment of the uterus }\end{array}$ & \\
\hline Negative HIV and hepatitis B test re sults & \\
\hline No history of hepatitis C positivity & \\
\hline No type 1 diabetes & \\
\hline No history of Rhesus or Kell alloimmunization & \\
\hline No history of platelet alloimmunization & \\
\hline $\begin{array}{c}\text { No history of previous spontaneous delivery } \\
\text { at less than } 27 \text { weeks gestation }\end{array}$ & \\
\hline $\begin{array}{l}\text { No history of uncontrolled hypertension, } \\
\text { chronic hypertension with end-organ disease, } \\
\text { or new-onset hypertension in the current pregnancy }\end{array}$ & \\
\hline $\begin{array}{l}\text { No medical condition that would contraindicate } \\
\text { general anesthesia or abdominal surgery }\end{array}$ & \\
\hline Placental abruption??? & \\
\hline
\end{tabular}

\begin{tabular}{|c|c|c|}
\hline \multicolumn{2}{|c|}{ Table 2: Neurologic Levels of Joint Function } \\
\hline \multirow{2}{*}{ Hip } & flexion & $\mathrm{T} 12, \mathrm{~L} 1, \mathrm{~L} 2, \mathrm{~L} 3$ \\
\cline { 2 - 3 } & extension & $\mathrm{S} 1$ \\
\hline \multirow{2}{*}{ Knee } & flexion & $\mathrm{L} 5, \mathrm{~S} 1$ \\
\cline { 2 - 3 } & extension & $\mathrm{L} 2, \mathrm{~L} 3, \mathrm{~L} 4$ \\
\hline \multirow{4}{*}{ ankle } & dorsiflexion & $\mathrm{L} 4, \mathrm{~L} 5$ \\
\cline { 2 - 3 } & plantar flexion & $\mathrm{S} 1, \mathrm{~S} 2$ \\
\cline { 2 - 3 } & inversion & $\mathrm{L} 4$ \\
\cline { 2 - 3 } & eversion & $\mathrm{S} 1$ \\
\hline
\end{tabular}




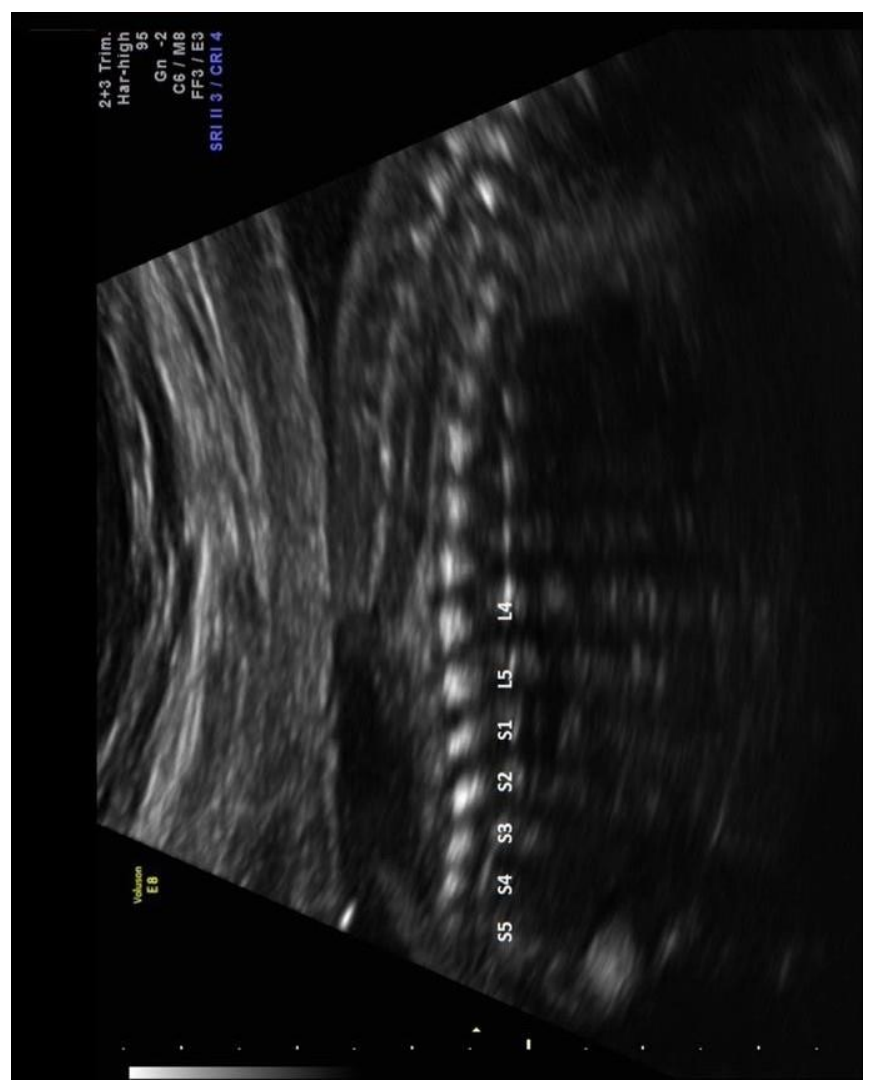

Figure 1-MRI of spinal defect starting at the L4 level

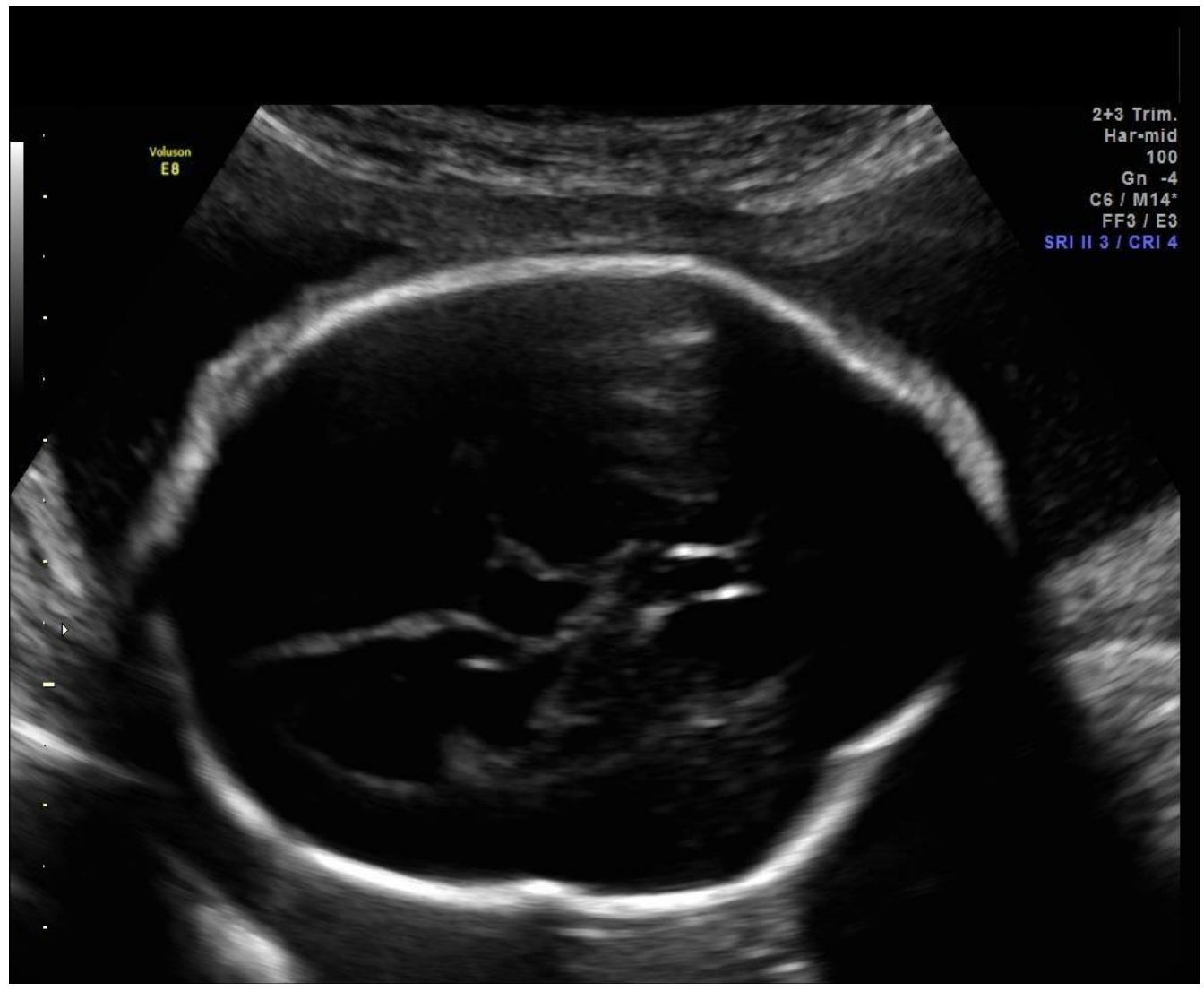

Figure 2-Lemon-shaped skull 


\section{References}

1. Adzick NC, Thom EA, Spong CY, et al. (2011). A randomized trial of prenatal versus postnatal repair of myelomeningocele. $N$ Eng J Med; 364:993-1004.

2. Pruitt LJ. (2012). Living with spina bifida: a historical perspective. Pediatrics; 130(2):181-183.

3. Lee NG, Gomez P, Uberoi V, et al. (2012). In utero closure of myelomeningocele does not improve lower tract function. $J$ Urol;188(4 Suppl):1567-1571.

4. Horst M, Mazzone L, Schraner T, et al. (2017). Prenatal myelomeningocele repair: Do bladders better? Neurourolo Urodyn ; 36(6):1651-1658.

5. Sawyer SM, Roberts KV. (1999). Sexual and reproductive health in young people with spina bifida. Dev Med Child Neurol; 41: 671-675.

6. Decter RM, Furness PD, Nguyen TA, et al. (1997). Reproductive understanding, sexual functioning and testosterone levels in men with spina bifida. J Urol; 157:1466. 